\title{
Photocatalytic Reaction of Gas-Phase Naphthalene on Paint- and Sunscreen-Coated Surfaces
}

\author{
Nicholas A. Ashley, Noelle McBride, Jason Krumholt, \\ Breeana Baker, and Kalliat T. Valsaraj \\ Cain Department of Chemical Engineering, Louisiana State University, Baton Rouge, LA 70803, USA \\ Correspondence should be addressed to Kalliat T. Valsaraj, valsaraj@lsu.edu
}

Received 15 June 2012; Accepted 12 August 2012

Academic Editors: H. Idriss and E. Van Steen

Copyright $\odot 2012$ Nicholas A. Ashley et al. This is an open access article distributed under the Creative Commons Attribution License, which permits unrestricted use, distribution, and reproduction in any medium, provided the original work is properly cited.

\begin{abstract}
The uses of metal oxide nanoparticles in modern paint and sunscreen formulations are widespread. Through materials characterization and kinetic experiments, it is demonstrated that fresh surface coatings of paint and sunscreen photocatalytically degrade gaseous naphthalene. The primary metal oxides are $\mathrm{TiO}_{2}$ in the form of the rutile phase in paint and as anatase in sunscreen formulations. Other metal oxides present are $\mathrm{Al}_{2} \mathrm{O}_{3}$ and $\mathrm{ZnO}$. Several organic fillers that are photochemically active are also present in paint and sunscreen samples but are unidentified. Reaction rate constants increased with increasing air relative humidity, due to the production of surface hydroxyl radical, and decreased with increasing coating thickness, due to mass transfer limitations. Photocatalytic degradation on these freshly generated surfaces is observed to be fast, with naphthalene half-lives shorter than 30 minutes. This work demonstrates that large, semivolatile organic compounds can react photochemically on freshly generated paint- and sunscreen-coated surfaces and may impact air quality in both indoor and outdoor environments.
\end{abstract}

\section{Introduction}

The widespread commercial use of nanotechnology has farreaching environmental impacts and implications. Modern paint and sunscreen formulations contain large quantities of ultrafine metal oxide particles, often between 10 and 20 weight percent in paints, and up to 25 weight percent in sunscreens [1-4]. Micron-sized $\mathrm{TiO}_{2}$ has been used for many years as a UV absorber and pigmentary agent. The use of nanoscale metal oxides in these formulations dramatically increases the total number of particles and specific surface area relative to their micron-sized counterparts. Since some of these metal oxides are well-known photocatalysts, this can also dramatically increase their reactivity towards gas-phase pollutants.

The photocatalytic degradation of small organic molecules, such as formaldehyde, methanol, and 2-propanol, on paint-coated surfaces or thin films containing embedded $\mathrm{TiO}_{2}$ nanoparticles has been studied [5-10]. To date, few studies have examined the destruction of large, semivolatile organic compounds (SVOCs) on paint films. Naphthalene is a representative SVOC. It is a common air pollutant, a byproduct of incomplete combustion of industrial processes, and is widespread [11]. Photocatalytic destruction of SVOCs is of particular importance since a variety of partial oxidation products further give rise to secondary organic aerosol (SOA) in air [12]. Some of the naphthalene partial oxidation products are known to be toxic, and more hazardous to human health than the parent compound [11]. Thus, naphthalene degradation on paint- and sunscreencoated surfaces to partially oxidized products, or complete mineralization to $\mathrm{CO}_{2}$, may even affect local ambient air quality. Because interior paint also contains high loadings of photoactive metal dioxide nanoparticles, the potential exists for indoor air quality to be also affected.

In addition to photocatalytic reactions on paint-coated surfaces, sunscreen products which contain metal oxide nanoparticles may also support photocatalytic transformations on the material surface. In this capacity, human skin serves as a substrate on which photocatalytic reactions can take place. Several studies have already demonstrated the potential dangers to human skin in contact with reactive 
oxygen species (ROS) produced by photo-excited nanoparticles $[4,13-20]$. To date, few researchers have examined the photocatalytic degradation of volatile or semi-volatile species on sunscreen surfaces.

The primary objective of this work is to demonstrate that paint- and sunscreen-coated surfaces are photocatalytically active towards gaseous, semi-volatile species. Reaction kinetics is studied as a function of both material thickness and ambient relative humidity, inside batch reactors under controlled laboratory conditions and UV light illumination. Paint and sunscreen materials are characterized with respect to metal oxide content, crystalline phase, and surface structure in order to better understand and interpret the kinetic data. Finally, both gaseous and surface-adsorbed reaction products are evaluated.

\section{Materials and Methods}

Two types of paint were used and were obtained locally. Both are latex-based paints; one sample is an interior paint (P1), the other is an exterior paint (P2). The sunscreen (S1) sample (SPF 50) was obtained from a local retail store. Both paint and sunscreen materials were shaken prior to each use but otherwise were used straight from the container and not modified in any way. Naphthalene was obtained from Aldrich (99\%, scintillation grade).

2.1. Determination of Sample Metal Oxides Content. The metal oxide content $\left(\mathrm{TiO}_{2}, \mathrm{Al}_{2} \mathrm{O}_{3}\right.$, and $\left.\mathrm{ZnO}\right)$ of the paint and sunscreen samples was measured by acid digestion. The complete acid digestion procedure is available elsewhere [21]. Briefly, 0.1 grams of sample was added to a Teflon microwave digestion tube, to which was added a mixture of $70 \% \mathrm{HNO}_{3}, 48 \% \mathrm{HF}$, and $98 \% \mathrm{H}_{2} \mathrm{SO}_{4}$. The materials were then digested by microwave-assisted acid digestion in an Anton Paar Multiwave 3000 microwave system, following the US EPA Method 3052. Following digestion, the remaining liquid (which contained no suspended solids) was diluted with $3 \% \mathrm{HNO}_{3}$ and analyzed by ICP-MS (Perkin-Elmer ELAN 9000) following US EPA Method 6020. Blank samples were analyzed to subtract out background metal concentrations, and recoveries of $\mathrm{TiO}_{2}, \mathrm{Al}_{2} \mathrm{O}_{3}$, and $\mathrm{ZnO}$ were measured by digesting the pure powders using the same procedure. Recoveries of metal oxides were $16 \%, 6 \%$, and $54 \%$ for $\mathrm{TiO}_{2}$, $\mathrm{Al}_{2} \mathrm{O}_{3}$, and $\mathrm{ZnO}$, respectively. Sample concentrations measured by ICP-MS were then adjusted for the recovery of each metal oxide. Standard quality control procedures were used, including adding sample internal standards, and analyzing a minimum of 12 samples per paint or sunscreen sample.

2.2. Sample Preparation. Surface coatings of paint and sunscreen were prepared on one-half inch thick drywall discs. Paint discs were prepared by using a paint roller to coat the discs, in a procedure that would mimic the application of paint to an interior or exterior wall. "Thin" samples were given one coat of paint; "thick" samples were given two coats. Paint thicknesses were measured by a differential displacement apparatus described elsewhere [21], which can measure differences in coating thickness to four decimal places. The average thickness of a "thin" paint surface was $500 \pm 11 \mu \mathrm{m}$, whereas the average thickness of a "thick" paint surface was $1000 \pm 26 \mu \mathrm{m}$. For sunscreen, the estimated thickness of a "thin" surface was $533 \mu \mathrm{m}$, and the estimated thickness of a "thick" layer was $1040 \mu \mathrm{m}$. Sunscreen samples were prepared by spreading $5.0 \pm 0.1$ grams (thin) or $10.0 \pm 0.2$ grams (thick) of sunscreen uniformly across the top of a drywall disc. Paint samples were allowed to dry for a minimum of 48 hours before experiments; sunscreen samples were used wet, in keeping with attempting to mimic the natural state and application of these materials as closely as possible.

2.3. Experimental Apparatus. The experimental setup of the photoreactor is shown in Figure 1. The apparatus consists of two activated carbon beds to remove water and other contaminants from the high-pressure air stream, a naphthalene saturated vapor generator (SVG), a deionized water bubbler and hot plate (Thermolyne, Cimarec 2) to generate humidified air, the reactor/box apparatus, and a second carbon trap at the outlet to adsorb any residual naphthalene before the outlet stream was vented to the fume hood. Regulators on the air supply for the naphthalene saturated vapor generator and deionized water bubbler enabled control of the gas flow to each of these streams. The SVG was prepared by mixing hexane, naphthalene, and Chromosorb $\mathrm{P}$ (Supelco, acid washed, 60-80 mesh) overnight on a stir plate, then evaporating the solvent. The resulting naphthaleneloaded powder was used to fill a stainless steel packed column (0.5 in. O.D., 31.5 in. long).

Prior to beginning an experiment, valves V1 and V2 are opened and the vapor space inside each reactor is saturated with a mixture of naphthalene and humidified air for 10 hours. These two valves are then closed, to enable each of the three individual reactors to function in the batch mode throughout the photocatalytic experiment. During the batch experiments, the vapor phase inside each reactor is stirred by its own dedicated pump to maintain a homogeneous gasphase concentration.

An overhead view and picture of the reactor box setup and a schematic and picture of an individual reactor are shown in Figure 2. Each reactor is a custom-made cylindrical vessel (height $4.85 \mathrm{in}$., diameter $4.25 \mathrm{in}$.), with an internal volume of 1.0 liter after the drywall disc has been loaded into the bottom (for details, see [21]). Each reactor has a quartz window in front ( 3 in. $\times 3$ in. by $1 / 8$ in.) to enable illumination of the sample by the UV lights. The reactor is sealed with a flange lid, using a silicone gasket and twelve screws to generate an air-tight seal around the lid.

The reactor box is made of stainless steel and encloses two UV lamps (UVP, model \#F15T8, $280 \mathrm{~nm}<\lambda<390 \mathrm{~nm}$, $\left.\lambda_{\text {midpoint }}=302 \mathrm{~nm}\right)$ in the front for illumination of the three reactors. Average UV light intensity inside the reactors was measured by a radiometer (UVP UVX Radiometer with UVX-31 sensor) at $\lambda=310 \mathrm{~nm}$ and was found to be $1368 \pm 316 \mu \mathrm{W} \cdot \mathrm{cm}^{-2}$. The three individual reactors can be inserted into and removed from the box from the top. When the reactors are in place, the box provides an 


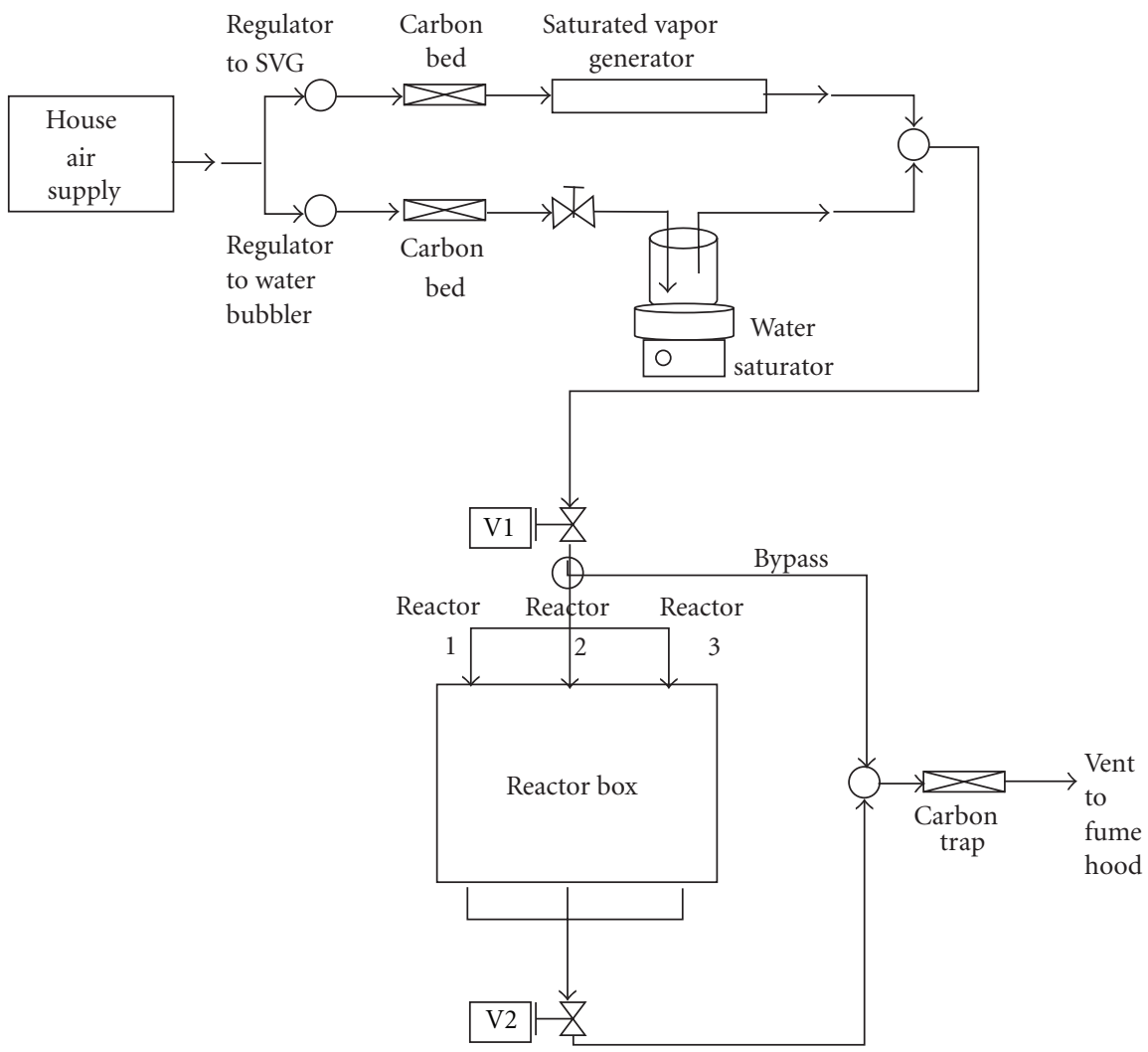

FIGURE 1: Experimental apparatus for photocatalytic reaction on paint and sunscreen surfaces. When saturating the gas-phase inside each reactor with naphthalene prior to the start of an experiment, valves V1 and V2 were open. Both valves were then closed prior to turning on the reactor pumps and UV lamps for an experiment, to enable batch operation of the 3 independent reactors during an experimental trial.

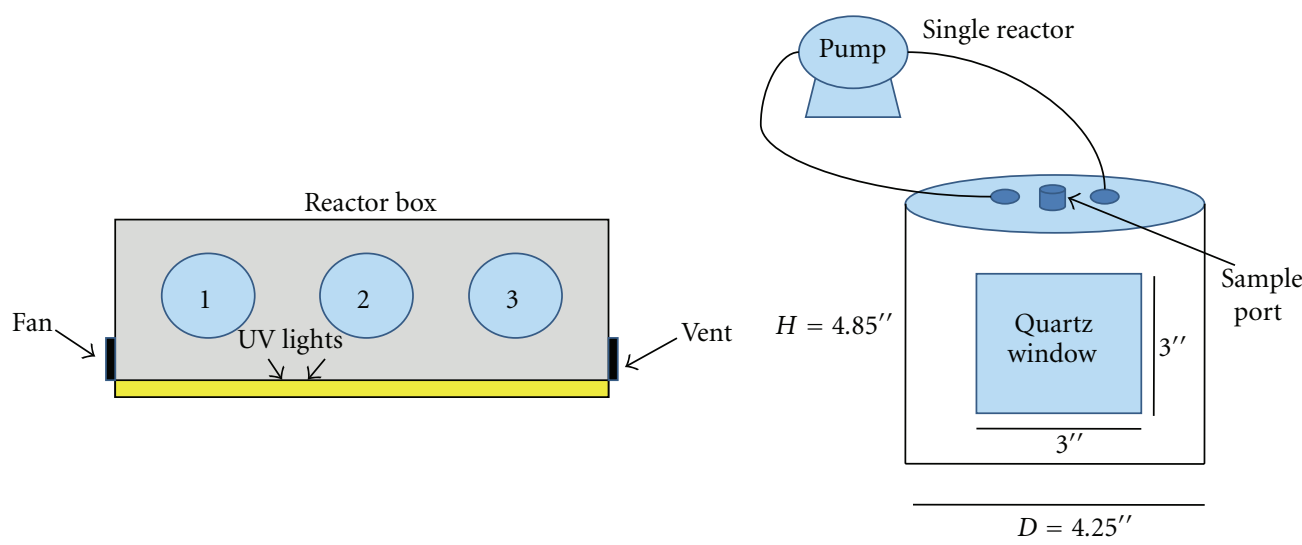

FIGURE 2: A schematic of the reactor box (view from the top) and individual reactor inside the box. Note that there are three such reactors inside the box.

enclosed environment where ambient light is blocked out, temperature is regulated to $30 \pm 5^{\circ} \mathrm{C}$, and illumination can be controlled by switching the UV lamps on or off. Each set of experimental conditions ( 3 materials, 2 thicknesses, and 2 values of relative humidity) was run twice in a series of three independent reactors, for a total of 6 independent data points per experiment at each sampling interval. Additional details of the experimental setup and procedure are provided elsewhere [21].
2.4. Gas-Phase Naphthalene Sampling and HPLC Analysis. Gas-phase samples were collected from each reactor using VICI Co. Pressure-Lok $2 \mathrm{~mL}$ syringes. The gas was bubbled into $2 \mathrm{~mL}$ GC vials (Agilent, with PTFE screw cap and red rubber septa), prefilled with $1.0 \mathrm{~mL}$ of acetonitrile (Mallinckrodt, 99.8\%, liquid chromatography/UV spectroscopy grade), and analyzed by HPLC (Hewlett Packard Series 1110 model with a Hewlett Packard 1046A fluorescence detector), using US EPA 550 method and several 


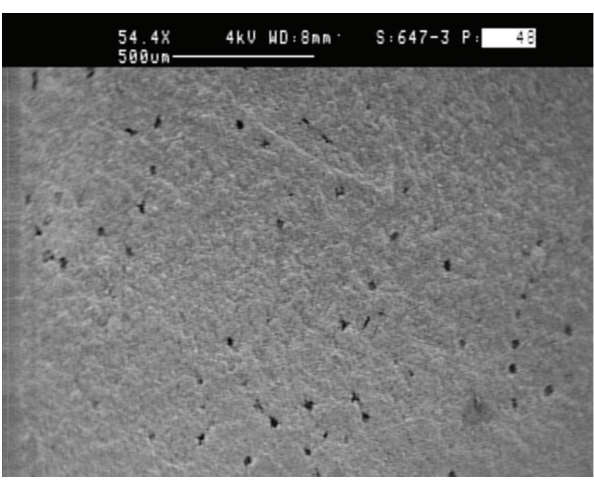

(a)

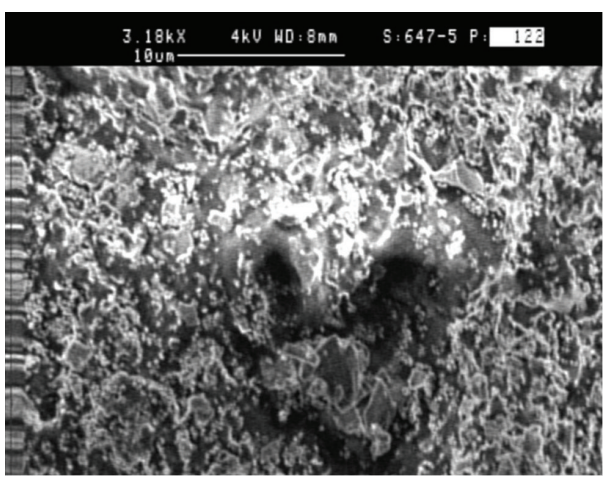

(b)

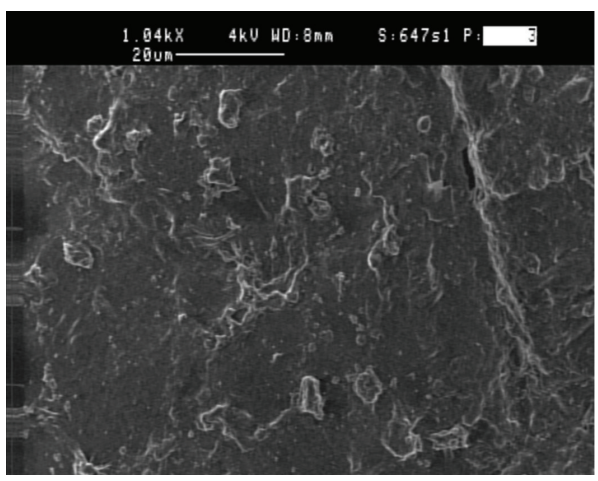

(c)

Figure 3: SEM images of (a) P2 paint surface structure, (b) metal oxide nanoparticles in sample P2, and (c) SEM image of sunscreen surface structure at $1.04 \mathrm{kX}$ magnification.

Application Notes by Agilent [22, 23]. A mixture of solvents ( $30 \%$ water, $70 \%$ acetonitrile), at a flow rate of $0.5 \mathrm{~mL} / \mathrm{min}$, is used as the mobile phase.

2.5. Product Analysis. Surface adsorbed products and residual surface adsorbed naphthalene are measured by extracting the pre- or postreacted paint or sunscreen surfaces in hexane, and analyzing the extract on the GC-MS (Agilent $6890 \mathrm{~N}$ GC with Agilent 5973 MSD). Further details of the surface extraction procedure are available elsewhere [21].

2.6. Scanning Electron Microscopy. For the interior paint, exterior paint, and sunscreen samples used in these experiments, the local surface structure, surface roughness,
TABLE 1: Metal oxide content of paint and sunscreen formulations used in photocatalysis experiments.

\begin{tabular}{lccc}
\hline & $\mathrm{TiO}_{2}($ wt $\%)$ & $\mathrm{Al}_{2} \mathrm{O}_{3}($ wt $\%)$ & $\mathrm{ZnO}$ (wt \%) \\
\hline P1 & $11.6 \% \pm 2.5 \%$ & $2.6 \% \pm 0.4 \%$ & $0.002 \% \pm 0.001 \%$ \\
P2 & $11.3 \% \pm 0.5 \%$ & $4.5 \% \pm 0.6 \%$ & $0.03 \% \pm 0.006 \%$ \\
S1 & $0.2 \% \pm 0.01 \%$ & $0.05 \% \pm 0.01 \%$ & $0.001 \% \pm 0.0002 \%$ \\
\hline
\end{tabular}

porosity, and $\mathrm{TiO}_{2}$ primary particle size must be determined because they directly affect the kinetic behavior of the photocatalytic reaction. SEM images were obtained on a Cambridge Stereoscan 260 SEM. Both reacted and unreacted surface samples of paint and sunscreen were imaged and were prepared using standard techniques.

2.7. X-ray Diffraction. The crystalline structure (anatase, rutile, or brookite) of the $\mathrm{TiO}_{2}$ phase is an important piece of information, since it impacts the reaction kinetics. Thin films of paint and sunscreen were prepared for Xray diffraction analysis by coating circular glass slides ( 1 in diameter, $1 / 8$ in thick) to a uniform thickness. As with the drywall coated samples for the reactors, paint samples were allowed to dry before analysis, while sunscreen was analyzed wet. Samples were processed on a Bruker/Siemens D5000 automated powder X-ray diffractometer with Rietveld analysis software. Library search routines were performed against standard diffraction patterns using the software, to determine the $\mathrm{TiO}_{2}$ crystalline phases. Pure anatase and rutile powder standards were also examined, to verify the sample diffraction patterns and library match results.

\section{Results and Discussion}

Acid digestion analysis reveals that the paint samples contain 11-12 wt $\% \quad \mathrm{TiO}_{2}$ and $3-5 \mathrm{wt} \% \quad \mathrm{Al}_{2} \mathrm{O}_{3}$. In contrast, the sunscreen sample used in these experiments contains less than $1 \mathrm{wt} \% \mathrm{TiO}_{2}$. The complete metal oxide analysis is provided in Table 1. Measured values of titanium dioxide content are in excellent agreement with ranges reported by the paint manufacturers in the material safety data sheets for the products. Sunscreen manufacturers do not report the $\mathrm{TiO}_{2}$ content of their formulation; however, the United States Food and Drug Administration has established $25 \mathrm{wt} \%$ as the maximum allowable limit for titanium dioxide in sunscreens.

Results of the XRD analysis indicate that for both paint samples, the primary $\mathrm{TiO}_{2}$ crystalline phase is rutile, whereas for sunscreen, the primary crystalline phase is anatase, which is consistent with previous studies [24-26]. Because anatase has a much greater photocatalytic activity than rutile, the naphthalene photocatalytic reaction kinetics are expected to be faster on sunscreen surfaces than on paint surfaces [2733].

Figure 3(a) shows an example SEM image of the P2 paint surface. As can be seen from the images, the surface is very rough and also very porous. The significant porosity of the surface is expected to increase mass transfer limitations, by retarding diffusion of the gaseous naphthalene into 
the surface pores. The surface roughness, especially at the microstructure level where the metal oxide nanoparticles are visible, increases both the number of particles and the particle surface area available for reaction and would be expected to increase the reaction rate of the gas-phase naphthalene on the paint surface. Figure 3(b) shows an SEM image of metal oxide nanoparticles on a paint-coated surface. As seen in the image, there are substantial amounts of nanoparticles in the paint, which agrees well with the metal oxide content shown previously. It is also important to note that the particles are mostly dispersed and exist as individual particles maintaining their nano size, not as agglomerates or clusters. This particle dispersion should be expected, since paints deliberately include several types of dispersants and fillers to prevent particle agglomeration and provide a uniform coating [34, 35]. Dispersed particles greatly increase the specific surface area available for the reaction and are expected to increase the reaction kinetics. Analysis of the SEM images reveals that the primary particle sizes in paint formulations is $125-175 \mathrm{~nm}$, while those in sunscreen are more monodisperse, at about $125 \mathrm{~nm}$. Compared to Figures 3(a) and 3(b), the surface morphology of a sunscreen-coated surface is very different than that of paint. The sunscreen surface shown in Figure 2(c) does not appear to be porous and contains significantly fewer particles than paint surfaces, which is in good agreement with the metal oxide analysis.

Rate constants were obtained by finding the average and standard deviation of the slope of $\ln \left(C_{A} / C_{A 0}\right)$ versus $t$ plot, at each set of conditions. $5 \%$ of the average was added to the standard deviation to account for HPLC analytical error, because the linear calibration over the course of the experimental trials drifted by as much as $5 \%$. Thus, the reported error in the rate constants and the error bars on the forthcoming concentration versus time plots include all experimental, measurement, and analytical errors. The calculated rate constants were then normalized by particle specific surface area as well as available mass of $\mathrm{TiO}_{2}$, in order to eliminate dependence due to specific surface area and catalyst mass from the experimentally determined firstorder rate constants.

For the batch reactor experiments, the fractional conversion of gaseous naphthalene is given by [36]

$$
f_{A}=\frac{C_{A 0}-C_{A}}{C_{A 0}},
$$

where $f_{A}$ is fractional conversion of naphthalene, $C_{A 0}$ is initial gas-phase naphthalene concentration $\left(\mu \mathrm{g} \mathrm{L}^{-1}\right)$, and $C_{A}$ is final gas-phase naphthalene concentration $\left(\mu \mathrm{g} \mathrm{L}^{-1}\right)$.

Seventy minutes was found to be the shortest reaction time of any experiment, the time at which gasphase naphthalene concentrations in the reactor dropped below detectable limits; the fractional conversions for all experiments are therefore reported at 70 minutes, to enable comparisons among materials and experimental conditions.

Results of the naphthalene background experiments are shown in Figure 4. Two types of background data were collected, one set in which the UV lights were turned on with uncoated drywall discs inside the reactors, and another set in which paint- or sunscreen-coated discs were used,

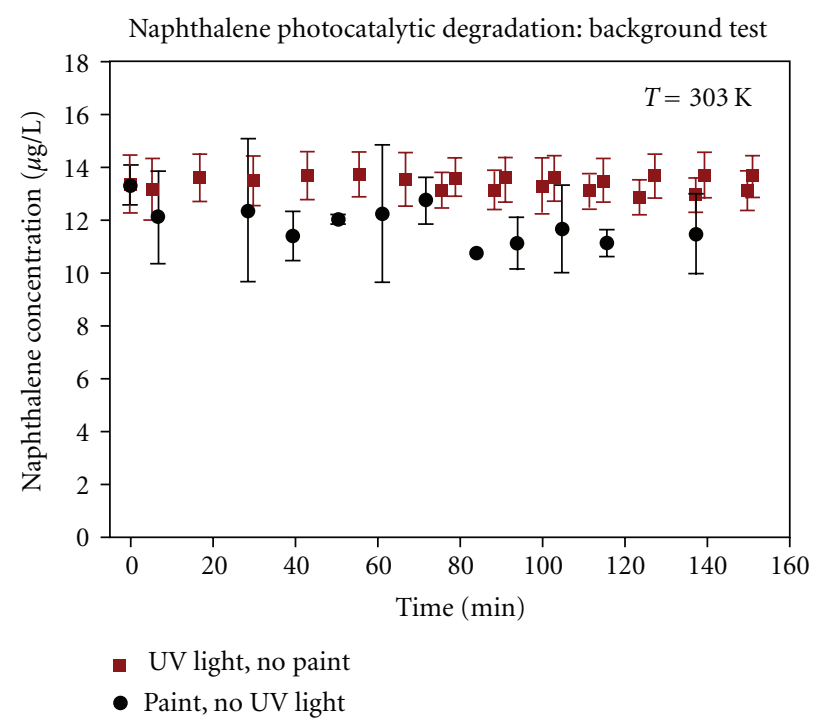

FIGURE 4: Background experiments of the photoreaction of gasphase naphthalene without paint or UV light.

but the UV lights remained off. No loss of naphthalene by reaction occurs in either experiment; therefore, for a photocatalytic reaction of gas-phase naphthalene to occur, both a paint/sunscreen surface and UV light must be present.

Figures 5, 6, and 7 show comparisons of reaction data at $30 \%$ and $70 \%$ relative humidities for the three surfaces (P1, P2, and S1). For experiments at 30\% relative humidity, the naphthalene degradation is faster on thin surfaces than on thick surfaces, likely reflecting the role played by the pore-diffusion resistance to mass transfer. At 70\% relative humidity, fewer differences are observed between thin and thick surfaces, because at high relative humidity, generation of hydroxyl radicals by the photocatalyst at high water vapor concentration likely dominates the system.

Table 2 gives the calculated rate constants, naphthalene fractional conversion, and half-lives, for all experiments. The rate constants reflect the trends previously observed in Figures 5-7 that photocatalytic degradation of gas-phase naphthalene is generally faster on thin surfaces than on thick surfaces, and at higher relative humidity. The seemingly low fractional conversions on paint surfaces are a consequence of calculating the conversions at a standard time. Because the reactions on sunscreen surfaces are faster, naphthalene gas-phase concentrations drop below detection limits sooner than for experiments with either paint. If fractional conversion is calculated at the end time for each experiment, naphthalene fractional conversions on interior and exterior paint surfaces are nearly all greater than $96 \%$. Analysis of the normalized rate constants, based on particle specific surface area or available photocatalyst, reveals no new insights into the data. As previously discussed, a variety of factors influence the observed surface reaction rates, including surface morphology, porosity, and mass transfer characteristics, as well as particle size, surface area, and crystalline phase.

As paint and sunscreen are complex mixtures of polymers, solvents, pigmentary agents, stabilizers, and 
TABLE 2: Calculated rate constants, half-lives, and fractional conversions for naphthalene photocatalytic degradation experiments.

\begin{tabular}{|c|c|c|c|c|c|}
\hline & $\begin{array}{l}\text { Rate constant } \\
\qquad\left(\min ^{-1}\right)\end{array}$ & $\begin{array}{l}\text { Normalized rate constant based } \\
\text { on specific surface area } \\
\left(\mathrm{g} \mathrm{min}^{-1} \mathrm{~cm}^{-2}\right)\end{array}$ & $\begin{array}{c}\text { Normalized rate constant } \\
\text { based on available } \mathrm{TiO}_{2} \\
\left(\mathrm{~min}^{-1} \mathrm{~g}^{-1}\right)\end{array}$ & $\begin{array}{l}\text { Half-life } \\
\text { (min) }\end{array}$ & $\begin{array}{c}\text { Fractional } \\
\text { conversion at } \\
t=70 \mathrm{~min}\end{array}$ \\
\hline \multicolumn{6}{|l|}{$30 \% \mathrm{RH}$} \\
\hline P1 thin & $0.023 \pm 0.006$ & $2.23 \times 10^{-7}$ & 150 & 30.1 & $70 \%$ \\
\hline P1 thick & $0.020 \pm 0.007$ & $1.94 \times 10^{-7}$ & 170 & 34.7 & $68 \%$ \\
\hline P2 thin & $0.024 \pm 0.006$ & $2.54 \times 10^{-7}$ & 53.0 & 28.9 & $81 \%$ \\
\hline P2 thick & $0.012 \pm 0.002$ & $1.27 \times 10^{-7}$ & 26.5 & 57.8 & $61 \%$ \\
\hline S1 thin & $0.044 \pm 0.024$ & $3.48 \times 10^{-7}$ & 1730 & 15.8 & $94 \%$ \\
\hline S1 thick & $0.033 \pm 0.009$ & $2.61 \times 10^{-7}$ & 1300 & 21.0 & $88 \%$ \\
\hline \multicolumn{6}{|l|}{$70 \% \mathrm{RH}$} \\
\hline P1 thin & $0.025 \pm 0.0046$ & $2.43 \times 10^{-7}$ & 162 & 27.7 & $86 \%$ \\
\hline P1 thick & $0.036 \pm 0.012$ & $3.49 \times 10^{-7}$ & 311 & 19.3 & $90 \%$ \\
\hline P2 thin & $0.029 \pm 0.011$ & $3.07 \times 10^{-7}$ & 64.1 & 23.9 & $87 \%$ \\
\hline P2 thick & $0.024 \pm 0.010$ & $2.54 \times 10^{-7}$ & 53.0 & 28.9 & $80 \%$ \\
\hline S1 thin & $0.061 \pm 0.025$ & $4.83 \times 10^{-7}$ & 2400 & 11.4 & $96 \%$ \\
\hline S1 thick & $0.049 \pm 0.025$ & $3.88 \times 10^{-7}$ & 1920 & 14.1 & $95 \%$ \\
\hline
\end{tabular}

photosensitizers, a complete reaction mechanism cannot presently be proposed. However, due to the high concentration of metal oxide particles in the formulation, combined with the well-known photocatalytic activity of titanium dioxide, several reasonable conclusions can be drawn to interpret the experimental data collected herein $[28,30]$. Even though the titanium dioxide content of paint is substantially higher than that of sunscreen, reaction rates on sunscreen surfaces, thick or thin, are significantly faster than those on paint at any thickness. This is a consequence of the different phases of $\mathrm{TiO}_{2}$ nanoparticles used in paint and sunscreen. The anatase titanium dioxide used in sunscreen is widely accepted to have much greater photocatalytic activity, especially in the UV regime, than the rutile $\mathrm{TiO}_{2}$ particles used in paint. A more active photocatalyst, combined with a high specific surface area, results in much faster reaction kinetics on sunscreen, even in the presence of fewer total particles. Calculation of the quantum yield for these experiments also confirms this trend.

The quantum yield is an important parameter in photocatalytic processes and can provide a measure of how efficiently the photocatalyst uses the incident UV light to drive the chemical reaction. The incident photon flux was measured in each reactor using a UVP UVX Radiometer with UVX-31 sensor $(\lambda=310 \mathrm{~nm})$. Results for the three reactors were averaged, to yield a photon flux of $1368 \mu \mathrm{W} / \mathrm{cm}^{2}$. The quantum yield is plotted against catalyst mass (Figure 8) to enable comparison among materials of differing catalyst content.

Once the photon flux was measured, the quantum yield was calculated for each experiment using the following equation [37]:

$$
\mathrm{QY}_{I}=\frac{R}{\phi_{I}},
$$

where $\mathrm{QY}_{I}$ is quantum yield (dimensionless) based on light incident on surface, $\phi_{I}$ is photon flux $\left(\mu \mathrm{mol} \mathrm{min}{ }^{-1}\right)$ incident on the paint/sunscreen coated surface, and $R$ is reaction rate $\left(\mu \mathrm{mol} \mathrm{min}^{-1}\right)$.

It is also important to note that the quantum yield is often (more correctly) defined with respect to the amount of photons absorbed by the surface (or photocatalyst). Because the photon absorption could not be measured for this system, the incident photons must be used to calculate the quantum yield, which prevents comparisons from being drawn between this system and other photocatalytic thin films. Of the total UV light incident on the surface, only a fraction is generally absorbed by the photocatalyst while the remainder is reflected; in this regard, the quantum yield calculated here is expected to underestimate the actual quantum yield based on UV light absorption by the photocatalyst.

The quantum yield for the reaction plotted against mass of available $\mathrm{TiO}_{2}$ photocatalyst is shown in Figure 8 . The plot demonstrates that the conversion efficiency of $\mathrm{TiO}_{2}$ particles in sunscreen is greater than that for paint, on a unit mass of catalyst basis. This result is consistent with the XRD analysis, which showed that the predominant $\mathrm{TiO}_{2}$ phase in sunscreen is anatase, whereas that in paint is rutile. Because anatase $\mathrm{TiO}_{2}$ has a much greater photocatalytic activity than rutile $\mathrm{TiO}_{2}$, the conversion of naphthalene on sunscreencoated surfaces should be more efficient. The quantum yield results demonstrate that a greater fraction of the UV light incident on a sunscreen-coated surface is used to drive the photocatalytic reaction than on paint-coated surfaces. In all systems shown in Figure 8, the quantum yield is very low. Much of the UV light incident on the surface is absorbed by the organic fillers, binders, and dispersants, which are also photochemically active, or is simply scattered by the surface and reflected away and is not used to drive the photocatalytic reactions on $\mathrm{TiO}_{2}$ surfaces $[10,34]$. The quantum yield per mass of photocatalyst is significantly greater for sunscreen 


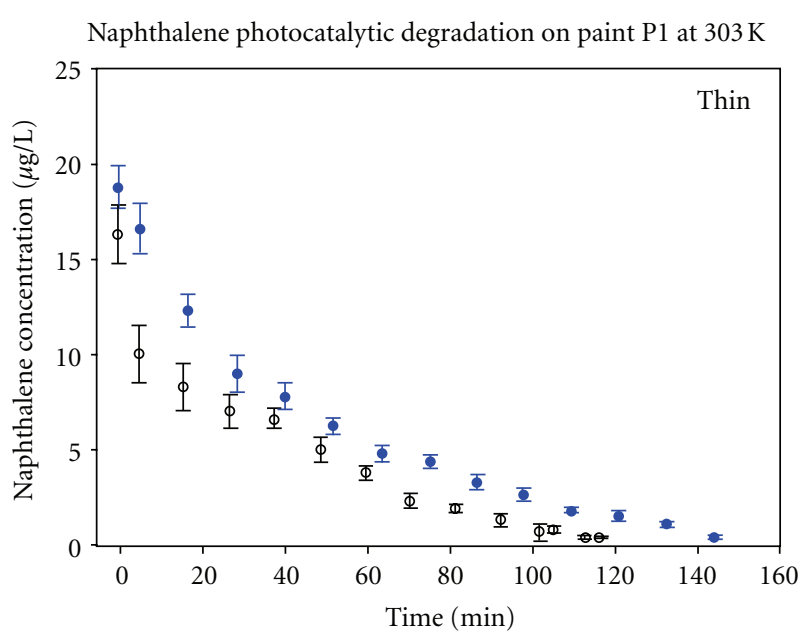

(a)

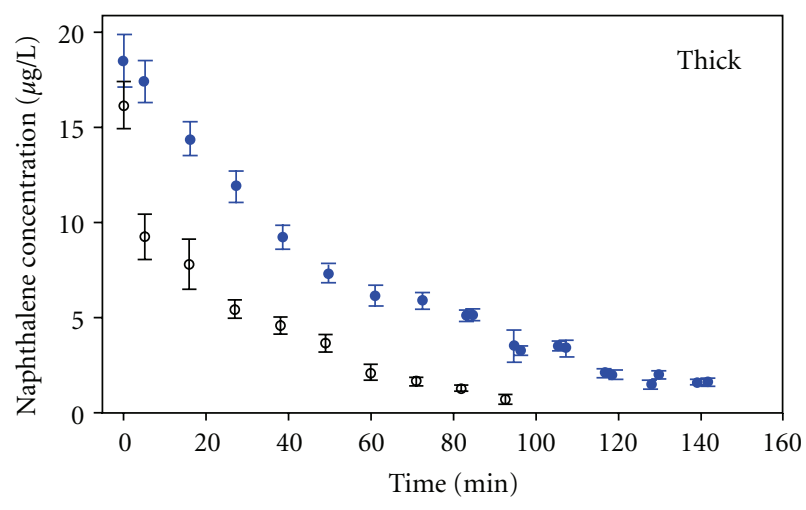

- Relative humidity $30 \%$

- Relative humidity $70 \%$

(b)

Figure 5: Photocatalytic reaction of gas-phase naphthalene on paint-coated surface (P1). Experiments at $30 \%$ and $70 \%$ relative humidities are shown.

systems than for paint systems, due to the presence of the more photocatalytically active $\mathrm{TiO}_{2}$ phase used in sunscreens (anatase) compared to paints (rutile).

At $30 \%$ relative humidity, pore diffusion resistance to mass transfer dominates the system for both types of paint and sunscreen. Rate constants at 30\% relative humidity for "thin" surfaces are always faster than for "thick" surfaces. For porous paint materials, thicker surfaces imply deeper pores, which mean that a naphthalene molecule must diffuse farther within the material and deeper inside the pore to reach a photo-active particle. For nonporous sunscreen surfaces, which also have lower metal dioxide content, naphthalene must diffuse deeper inside the material to encounter a photocatalyst particle and react. This additional diffusion resistance retards the naphthalene reaction kinetics and is reflected in the observed rate constants.

The Thiele Modulus and effectiveness factor are important parameters for catalytic processes and provide a quantitative measure of mass transfer (pore diffusion) and kinetic

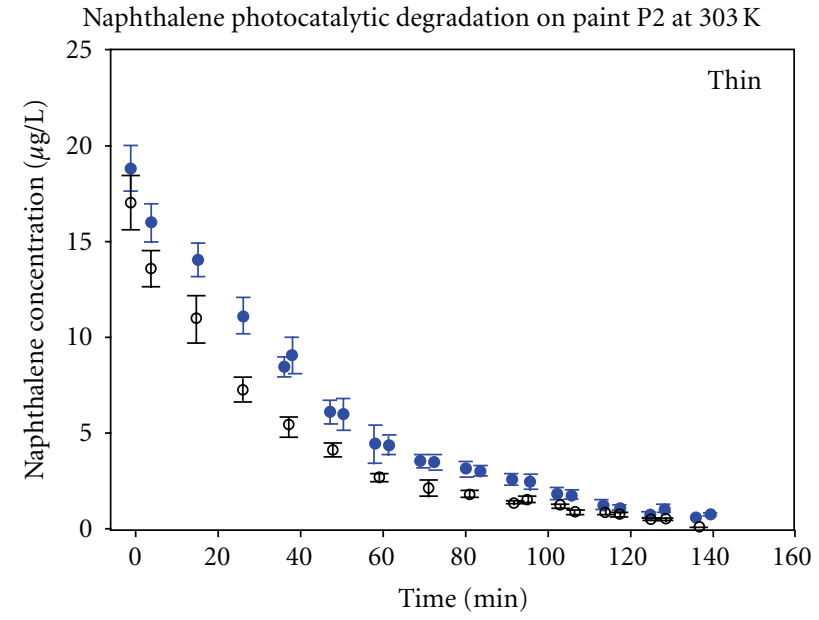

(a)

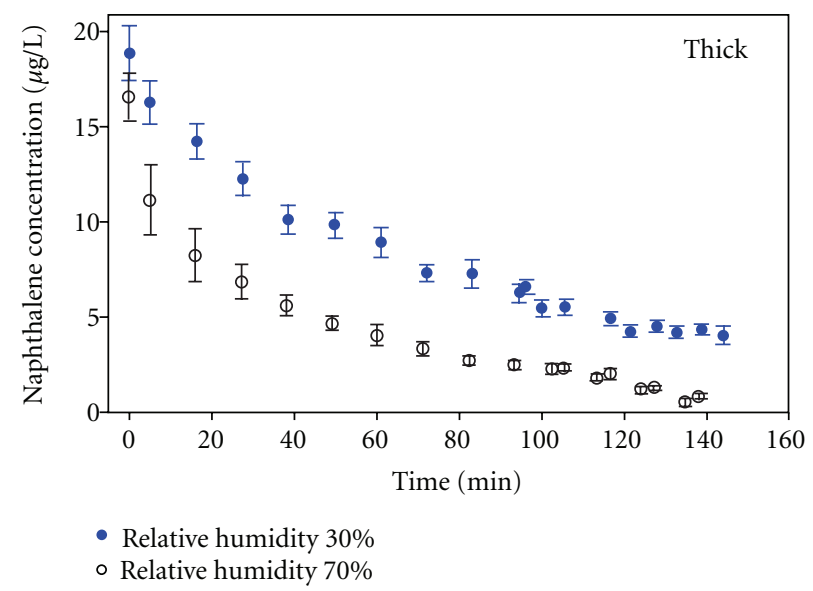

(b)

Figure 6: Photocatalytic reaction of gas-phase naphthalene on paint-coated surface (P2). Experiments at 30\% and 70\% relative humidities are shown.

limitations. The Thiele Modulus and effectiveness factor can be determined for the paint experiments. The major assumption for the calculation include: a flat plate geometry, reaction occurs on and within the paint material but only at catalyst particle, surfaces, a first-order irreversible reaction, and that the system is isothermal $[36,38]$. The Thiele Modulus is then calculated from the following equation [36]:

$$
\phi=L\left(\frac{k}{D_{\text {eff }}}\right)^{1 / 2}
$$

where $\phi$ is Thiele Modulus (dimensionless), $L$ is thickness of the paint layer $(\mathrm{cm}), k$ is first-order reaction rate constant $\left(\mathrm{min}^{-1}\right)$, and $D_{\text {eff }}$ is effective diffusion coefficient $\left(\mathrm{cm}^{2} \mathrm{sec}^{-1}\right)$.

The effectiveness factor is defined as the ratio of the observed reaction rate to the surface reaction rate in the absence of mass transfer limitations. The effectiveness factor 


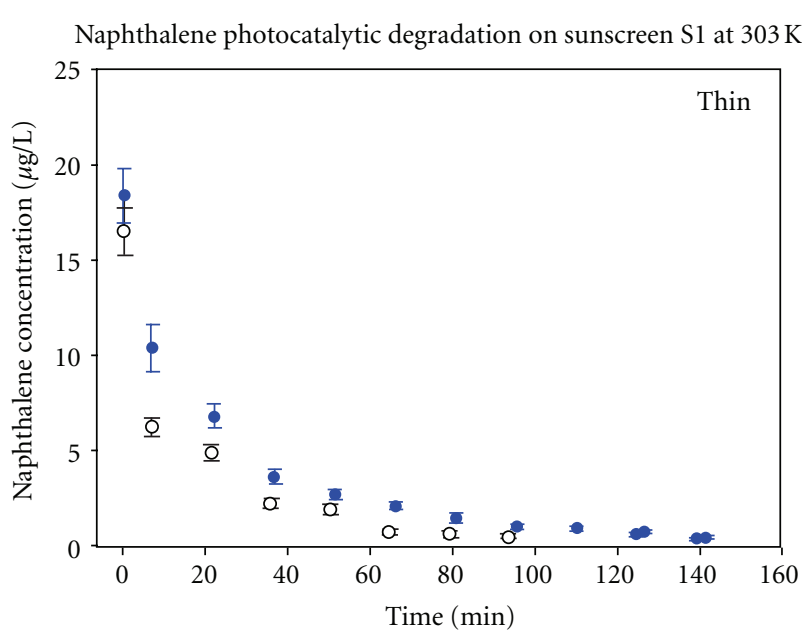

(a)

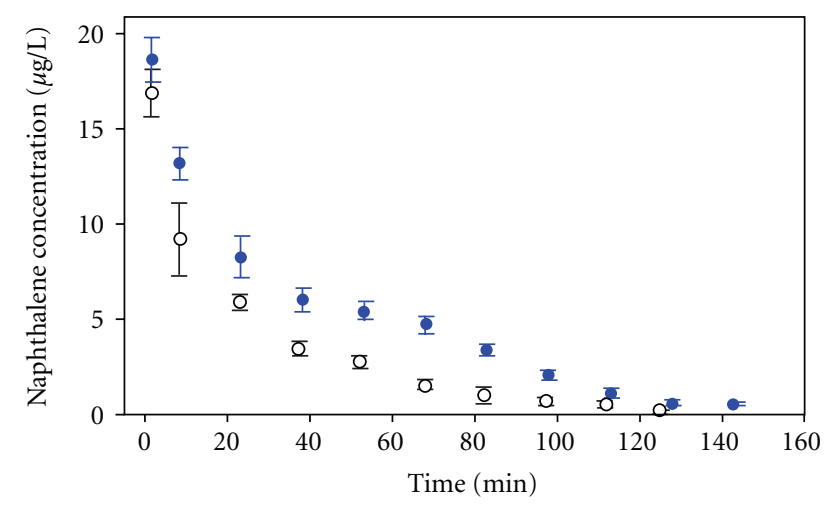

- Relative humidity $30 \%$

- Relative humidity $70 \%$

(b)

Figure 7: Photocatalytic reaction of gas-phase naphthalene on sunscreen-coated surface (S1). Experiments at $30 \%$ and $70 \%$ relative humidities are shown.

for this system, subject to the previous assumptions, is given by [36]

$$
\eta=\frac{\tanh \phi}{\phi}
$$

where $\eta$ is effectiveness factor (dimensionless), $\phi$ is Thiele Modulus (dimensionless).

A small Thiele Modulus (or large effectiveness factor) implies that the reaction is kinetically (rate) limited, whereas a large Thiele Modulus (and small effectiveness factor) implies that the process is mass transfer (diffusion) limited [39]. Quantitatively, a Thiele Modulus greater than 5 reflects a strong-pore diffusion resistance to the catalytic reaction [36].

Finally, the Weisz-Prater criterion can be used as an alternate criterion to identify whether or not a catalytic reaction is diffusion limited. The Weisz-Prater criterion is defined as

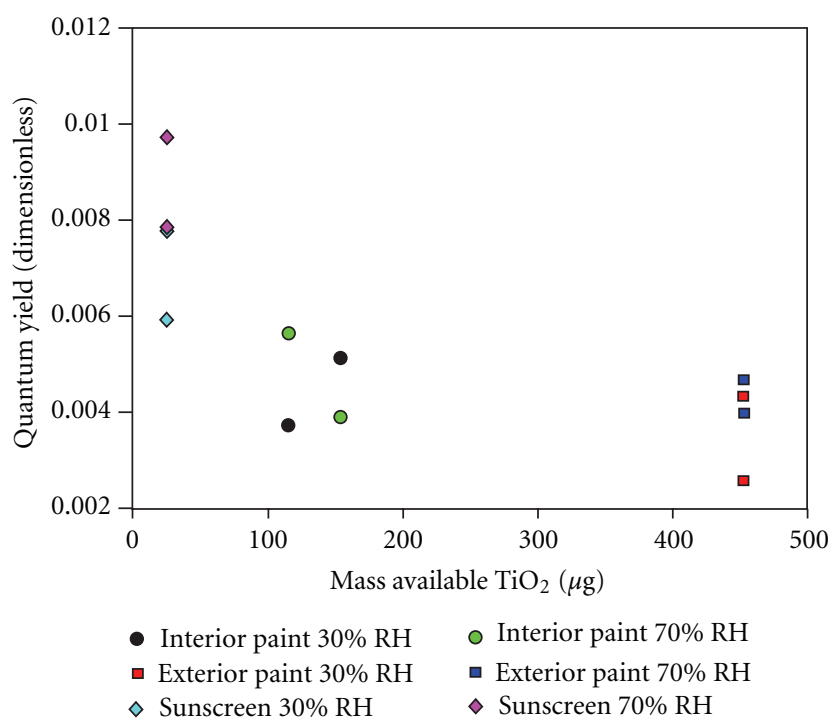

FIGURE 8: Quantum yield versus catalyst mass for all experiments.

ratio of the measured reaction rate to the rate of internal diffusion and is defined by the following equation [38]:

$$
C_{\mathrm{WP}}=\eta \phi^{2}
$$

where $C_{\mathrm{WP}}$ is the Weisz-Prater criterion, $\eta$ is effectiveness factor (dimensionless), and $\phi$ is Thiele Modulus (dimensionless).

If $C_{\mathrm{WP}}$ is much less than unity, concentration gradients within the pores are not significant, and the catalytic reaction is kinetically rate limited. If $C_{\mathrm{WP}}$ is much greater than unity, the rate of pore diffusion is very slow, and thus the process is diffusion limited. For $C_{\mathrm{WP}} \approx 1$, the reaction rate is nearly equal to the rate of diffusion within the catalytic system.

The Thiele Modulus, effectiveness factor, and WeiszPrater criterion for the exterior and interior paint systems are given in Table 3. The Weisz-Prater criteria are all much greater than unity, confirming that the reactions are indeed diffusion limited. In all cases, the calculated Thiele Modulus increases as the material thickness increases, reflecting the stronger mass transfer (pore diffusion) resistance for thicker materials. The increase in the Thiele Modulus and WeiszPrater criterion, and corresponding decrease in effectiveness factor at $70 \%$ relative humidity relative to $30 \%$ relative humidity, suggests that the experiments at $70 \%$ relative humidity are more strongly diffusion limited than those at low relative humidity. This also supports the capillary condensation hypothesis, which postulates that, as relative humidity increases, water vapor begins to condense and partially blocks some of the pores from being accessible to gas-phase reactants.

If the reaction at $70 \%$ relative humidity is subject to greater mass transfer resistance than that at 30\% relative humidity, a logical conclusion to explain the increased reaction rate at high relative humidity is the dominance of hydroxyl radical production on the surface of the photocatalyst relative to naphthalene diffusion within the pores of the paint material. If the hydroxyl radical production 
Table 3: Thiele Modulus, effectiveness factor, and Weisz-Prater criterion for paint systems used in these experiments.

\begin{tabular}{|c|c|c|c|}
\hline Material & Thiele Modulus $\phi$ & Effectiveness factor $\eta$ & Weisz-Prater criterion $C_{\mathrm{WP}}$ \\
\hline \multicolumn{4}{|c|}{$30 \%$ relative humidity } \\
\hline P1 thin & 84.8 & 0.012 & 84.8 \\
\hline P1 thick & 158 & 0.006 & 158 \\
\hline P2 thin & 21.5 & 0.046 & 21.5 \\
\hline P2 thick & 30.4 & 0.033 & 30.4 \\
\hline \multicolumn{4}{|c|}{$70 \%$ relative humidity } \\
\hline P1 thin & 88.4 & 0.011 & 88.4 \\
\hline P1 thick & 212 & 0.005 & 212 \\
\hline P2 thin & 23.7 & 0.042 & 23.7 \\
\hline P2 thick & 43.1 & 0.023 & 43.1 \\
\hline
\end{tabular}

by water photolysis on the surface of the particles at high relative humidity is sufficiently fast, hydroxyl groups are likely produced faster than the naphthalene can diffuse within the pores of the material, which implies that the naphthalene now needs only to diffuse and adsorb to the particles on the top, exposed surface of the paint layers to be degraded, and not further within the pores of the material. The pore-diffusion hypothesis is confirmed by calculation of the Thiele Modulus and effectiveness factor, provided above. Because a Thiele Modulus greater than 5 is indicative of a strong pore-diffusion resistance, resulting Modulus values for paint systems between 20 and 212 indicate that the observed naphthalene photocatalytic reaction rates are significantly mass transfer limited.

The mechanism of hydroxyl generation on photoactive $\mathrm{TiO}_{2}$ surfaces is well known [40-43]. As water vapor diffuses to the $\mathrm{TiO}_{2}$ nanoparticles in the presence of UV light, photogenerated holes on the titanium dioxide surface split the water into hydrogen ions and hydroxyl radicals, which subsequently attack the surface-adsorbed naphthalene. As the relative humidity of the system increases, the hydroxyl radical generation rate also increases, and the naphthalene molecules are more readily attacked by the photo-generated hydroxyl radicals at $70 \%$ relative humidity than at 30\% relative humidity. These results are in excellent agreement with other studies which have demonstrated faster photoreaction kinetics with increasing relative humidity [27].

The half-lives calculated for the reactions on paint and sunscreen surfaces shown in Table 1 reflect the overall kinetics previously discussed with the rate constants. Short halflives, most under 30 minutes, reinforce that the degradation of naphthalene on paint and sunscreen surfaces is very rapid. In addition, the high fractional conversions demonstrate the efficiency of the sunscreen over paint-coated surfaces in destroying gas-phase naphthalene. It should be noted that naphthalene fractional conversions on paint approach $96 \%$ or more when the entire two and a half hour reaction time is considered. The conversions reported in Table 1 are at $t=70$ minutes, which is the shortest reaction time of any experiment. Titanium dioxide nanoparticles had been previously shown to be very effective in degrading small organic molecules, such as $\mathrm{NO}_{x}$ and formaldehyde $[9,10$, $44]$. Results of the current experiments indicate that paint and sunscreen surfaces containing nanoparticles are also effective photocatalysts for degrading larger, semi-volatile organic compounds, such as naphthalene.

A mass balance on total carbon was carried out, in order to determine the photoreaction products and account for the recovery of the initial carbon (naphthalene) charged to the reactor at the beginning of each experiment. Paint systems are a complex mixture of organic polymers, binders, fillers, and dispersants, many of which can be photochemically degraded in the presence of UV light, or photocatalytically degraded by embedded titanium dioxide nanoparticles $[9$, $34,35]$. The photochemical or photocatalytic destruction of these components of the paint matrix often results in the formation of $\mathrm{CO}_{2}[25,35,45,46]$. For the paint and sunscreen systems studied here, the amount of $\mathrm{CO}_{2}$ evolved from the paint or sunscreen matrices during the experiment results in an amount of carbon significantly greater than the amount of carbon present as naphthalene at the start of the experiment. Two surface adsorbed reaction products were quantified by GC/MS: benzyl alcohol and phenol, both in quantities less than $2 \mu \mathrm{g}$. Therefore, surface adsorbed products are not likely to be the major reaction products, which imply that the bulk of the reaction products must be in the gas phase. In addition, naphthalene concentrations in the gas-phase as well as on the material surface at the conclusion of the experiment were below quantifiable detection limits; if the naphthalene is lost from the gas-phase and is not strictly adsorbed by the surface, the only other explanation for its disappearance is due to chemical reaction on the photocatalyst surface. Because the evolved $\mathrm{CO}_{2}$ overwhelms the batch reactor gas phase at the conclusion of each experiment, the carbon mass balance cannot be closed, and the quantification of gaseous photocatalytic reaction products remains undetermined.

\section{Environmental Implications}

The photocatalytic destruction of gaseous naphthalene on paint- and sunscreen-coated surfaces has been demonstrated through gas-phase experiments in batch reactors. The fast rate constants, short half-lives, and high fractional conversions demonstrate the efficiency of this process in degrading a large, semi-volatile organic compound on these surfaces 
under well-controlled laboratory conditions. To the best of our knowledge, this work is the first to demonstrate the photocatalytic degradation of SVOCs on paint surfaces and is also the first to report photoreaction kinetics of sunscreen materials due to the embedded $\mathrm{TiO}_{2}$ nanoparticles.

The next step involves experimental analysis of these surfaces under conditions which more accurately reflect those in the natural environment, that is, under a broader spectrum of both visible and ultraviolet light and intensities, as well as over a wider range of temperature and relative humidity conditions. Such experiments would not only provide relevant information as to the behavior of these photocatalytic surfaces under conditions which would be expected to be encountered during normal use of these products, but also would result in the important evaluation of the photocatalytic lifetimes of the surface, that is, how long the surfaces maintain their high photocatalytic activity when exposed to broader (and often harsher) natural conditions.

\section{Acknowledgments}

The authors acknowledge Wanda LeBlanc (LSU Geology \& Geophysics) for providing the XRD analysis, Cindy Henk (LSU Biology) for assistance with the SEM, and Joe Bell (LSU Chemical Engineering) for construction of the reactors and reactor box apparatus. N. Ashley is supported by a Donald W. Clayton Engineering Excellence Graduate Fellowship through the LSU College of Engineering. This work was funded by the Cain Department of Chemical Engineering at Louisiana State University.

\section{References}

[1] D. Dionysiou, "Environmental applications and implications of nanotechnology and nanomaterials," Journal of Environmental Engineering, vol. 130, no. 7, pp. 723-724, 2004.

[2] P. Biswas and C. Y. Wu, "Nanoparticles and the environment," Journal of the Air and Waste Management Association, vol. 55, no. 6, pp. 708-746, 2005.

[3] K. A. D. Guzmán, M. R. Taylor, and J. F. Banfield, "Environmental risks of nanotechnology: national nanotechnology initiative funding, 2000-2004," Environmental Science and Technology, vol. 40, no. 5, pp. 1401-1407, 2006.

[4] M. R. Wiesner, G. V. Lowry, P. Alvarez, D. Dionysiou, and P. Biswas, "Assessing the risks of manufactured nanomaterials," Environmental Science and Technology, vol. 40, no. 14, pp. 4336-4345, 2006.

[5] A. V. Vorontsov, E. N. Savinov, G. B. Barannik, V. N. Troitsky, and V. N. Parmon, "Quantitative studies on the heterogeneous gas-phase photooxidation of CO and simple VOCs by air over $\mathrm{TiO}_{2}$," Catalysis Today, vol. 39, no. 3, pp. 207-218, 1997.

[6] J. N. Wilson and H. Idriss, "Effect of surface reconstruction of $\mathrm{TiO}_{2}(001)$ single crystal on the photoreaction of acetic acid," Journal of Catalysis, vol. 214, no. 1, pp. 46-52, 2003.

[7] H. Yu, K. Zhang, and C. Rossi, "Theoretical study on photocatalytic oxidation of VOCs using nano- $\mathrm{TiO}_{2}$ photocatalyst," Journal of Photochemistry and Photobiology A, vol. 188, no. 1, pp. 65-73, 2007.

[8] Y. Ohko, A. Fujishima, and K. Hashimoto, "Kinetic analysis of the photocatalytic degradation of gas-phase 2-propanol under mass transport-limited conditions with a $\mathrm{TiO}_{2}$ film photocatalyst," Journal of Physical Chemistry B, vol. 102, no. 10, pp. 1724-1729, 1998.

[9] N. S. Allen, M. Edge, G. Sandoval, J. Verran, J. Stratton, and J. Maltby, "Photocatalytic coatings for environmental applications," Photochemistry and Photobiology, vol. 81, no. 2, pp. 279-290, 2005.

[10] T. Salthammer and F. Fuhrmann, "Photocatalytic surface reactions on indoor wall paint," Environmental Science and Technology, vol. 41, no. 18, pp. 6573-6578, 2007.

[11] B. J. McConkey, L. M. Hewitt, D. G. Dixon, and B. M. Greenberg, "Natural sunlight induced photooxidation of naphthalene in aqueous solution," Water, Air, and Soil Pollution, vol. 136, no. 1-4, pp. 347-359, 2002.

[12] H. J. L. Forstner, R. C. Flagan, and J. H. Seinfeld, "Secondary organic aerosol from the photooxidation of aromatic hydrocarbons: molecular composition," Environmental Science and Technology, vol. 31, no. 5, pp. 1345-1358, 1997.

[13] B. Vileno, M. Lekka, A. Sienkiewicz et al., "Stiffness alterations of single cells induced by UV in the presence of $\mathrm{NanoTiO}_{2}$ ,"Environmental Science and Technology, vol. 41, no. 14, pp. 5149-5153, 2007.

[14] T. J. Brunner, P. Wick, P. Manser et al., "In vitro cytotoxicity of oxide nanoparticles: comparison to asbestos, silica, and the effect of particle solubility," Environmental Science and Technology, vol. 40, no. 14, pp. 4374-4381, 2006.

[15] A. Nel, T. Xia, L. Mädler, and N. Li, "Toxic potential of materials at the nanolevel," Science, vol. 311, no. 5761, pp. 622627, 2006.

[16] R. Wedin, "Is nanotechnology safe?" Chemistry, pp. 48-50, 2006.

[17] T. C. Long, N. Saleh, R. D. Tilton, G. V. Lowry, and B. Veronesi, "Titanium dioxide (P25) produces reactive oxygen species in immortalized brain microglia (BV2): implications for nanoparticle neurotoxicity," Environmental Science and Technology, vol. 40, no. 14, pp. 4346-4352, 2006.

[18] R. R. Chianelli, M. J. Yacaman, J. Arenas, and F. Aldape, "Atmospheric nanoparticles in photocatalytic and thermal production of atmospheric pollutants," Journal of Hazardous Materials, vol. 1, no. 1, pp. 1-16, 1998.

[19] K. Donaldson, V. Stone, A. Clouter, L. Renwick, and W. MacNee, "Ultrafine particles," Occupational and Environmental Medicine, vol. 58, no. 3, pp. 211-216, 2001.

[20] B. M. Rothen-Rutishauser, S. Schürch, B. Haenni, N. Kapp, and P. Gehr, "Interaction of fine particles and nanoparticles with red blood cells visualized with advanced microscopic techniques," Environmental Science and Technology, vol. 40, no. 14, pp. 4353-4359, 2006.

[21] N. A. Ashley, Particle-chemical interactions and environmental chemodynamics of fine and ultrafine particles in a natural disaster scenario [Ph.D. thesis], Louisiana State University, Baton Rouge, La, USA, 2009.

[22] A. Gratzfeld-Husgen, R. Schuster, and H. Schulenberg-Schell, Polynuclear Aromatic Hydrocarbons by HPLC, Agilent Technologies, Waldbronn, Germany, 1993.

[23] A. Gratzfeld-Husgen and R. Schuster, Improved Data Quality in the Automated HPLC Analysis of PNAs (PAHs), Agilent Technologies, Waldbrom, Germany, 1995.

[24] J. H. Braun, A. Baidins, and R. E. Marganski, " $\mathrm{TiO}_{2}$ pigment technology: a review," Progress in Organic Coatings, vol. 20, no. 2, pp. 105-138, 1992.

[25] P. A. Christensen, A. Dilks, T. A. Egerton, E. J. Lawson, and J. Temperley, "Photocatalytic oxidation of alkyd paint films measured by FTIR analysis of UV generated carbon dioxide," 
Journal of Materials Science, vol. 37, no. 22, pp. 4901-4909, 2002.

[26] N. C. Debnath and S. A. Vaidya, "Application of X-ray diffraction technique for characterisation of pigments and control of paints quality," Progress in Organic Coatings, vol. 56, no. 2-3, pp. 159-168, 2006.

[27] K. Kakinoki, K. Yamane, R. Teraoka, M. Otsuka, and Y. Matsuda, "Effect of relative humidity on the photocatalytic activity of titanium dioxide and photostability of famotidine," Journal of Pharmaceutical Sciences, vol. 93, no. 3, pp. 582-589, 2004.

[28] A. L. Linsebigler, G. Lu Jr, and J. T. Yates, "Photocatalysis on $\mathrm{TiO}_{2}$ surfaces: principles, mechanisms, and selected results," Chemical Reviews, vol. 95, no. 3, pp. 735-758, 1995.

[29] C.-Y. Wang, H. Groenzin, and M. J. Shultz, "Surface characterization of nanoscale $\mathrm{TiO}_{2}$ film by sum frequency generation using methanol as a molecular probe," Journal of Physical Chemistry B, vol. 108, no. 1, pp. 265-272, 2004.

[30] M. A. Fox and M. T. Dulay, "Heterogeneous photocatalysis," Chemical Reviews, vol. 93, no. 1, pp. 341-357, 1993.

[31] Y.-H. Zhang, C. K. Chan, J. F. Porter, and W. Guo, "MicroRaman spectroscopic characterization of nanosized $\mathrm{TiO}_{2}$ powders prepared by vapor hydrolysis," Journal of Materials Research, vol. 13, no. 9, pp. 2602-2609, 1998.

[32] M. R. Hoffmann, S. T. Martin, W. Choi, and D. W. Bahnemann, "Environmental applications of semiconductor photocatalysis," Chemical Reviews, vol. 95, no. 1, pp. 69-96, 1995.

[33] Y. Wang, L. Zhang, K. Deng, X. Chen, and Z. Zou, "Low temperature synthesis and photocatalytic activity of rutile $\mathrm{TiO}$ 2 nanorod superstructutes," Journal of Physical Chemistry C, vol. 111, no. 6, pp. 2709-2714, 2007.

[34] M. P. Diebold, C. R. Bettler, and D. M. Mukoda, "Mechanism of $\mathrm{TiO}_{2} / \mathrm{ZnO}$ instability in latex paints," Journal of Coatings Technology, vol. 75, no. 942, pp. 29-8, 2003.

[35] S. H. Joo, S. R. Al-Abed, and T. Luxton, "Influence of carboxymethyl cellulose for the transport of titanium dioxide nanoparticles in clean silica and mineral-coated sands," Environmental Science and Technology, vol. 43, no. 13, pp. 49544959, 2009.

[36] R. W. Missen, C. A. Mims, and B. A. Saville, Introduction to Chemical Reaction Engineering and Kinetics, John Wiley \& Sons, New York, 1999.

[37] C.-Y. Wang, R. Pagel, D. W. Bahnemann, and J. K. Dohrmann, "Quantum yield of formaldehyde formation in the presence of colloidal $\mathrm{TiO}_{2}$-based photocatalysts: effect of intermittent illumination, platinization, and deoxygenation," Journal of Physical Chemistry B, vol. 108, no. 37, pp. 14082-14092, 2004.

[38] H. S. Fogler, Elements of Chemical Reaction Engineering, Prentice Hall, New York, NY, USA, 3rd edition, 1999.

[39] O. Levenspiel, Chemical Reaction Engineering, John Wiley \& Sons, New York, NY, USA, 3rd edition, 1999.

[40] K. I. Ishibashi, A. Fujishima, T. Watanabe, and K. Hashimoto, "Generation and deactivation processes of superoxide formed on $\mathrm{TiO}_{2}$ film illuminated by very weak UV light in air or water," Journal of Physical Chemistry B, vol. 104, no. 20, pp. 4934-4938, 2000.

[41] K. I. Ishibashi, Y. Nosaka, K. Hashimoto, and A. Fujishima, "Time-dependent behavior of active oxygen species formed on photoirradiated $\mathrm{TiO}_{2}$ films in air," Journal of Physical Chemistry B, vol. 102, no. 12, 1998.

[42] A. Fujishima, T. N. Rao, and D. A. Tyrk, "Titanium dioxide photocatalysis," Journal of Photochemistry and Photobiology C, vol. 1, no. 1, pp. 1-21, 2000.
[43] M. Anpo, T. Shima, and Y. Kubokawa, "ESR and photoluminescence evidence for the photocatalytic formation of hydroxyl radicals on small $\mathrm{TiO}_{2}$ particles," Chemistry Letters, vol. 14, no. 12, pp. 1799-1802, 1985.

[44] N. S. Allen, M. Edge, J. Verran, J. Stratton, J. Maltby, and C. Bygott, "Photocatalytic titania based surfaces: environmental benefits," Polymer Degradation and Stability, vol. 93, no. 9, pp. 1632-1646, 2008.

[45] C. Q. Jin, P. A. Christensen, T. A. Egerton, and J. R. White, "Rapid measurement of photocatalytic oxidation of poly(vinyl chloride) by in situ FTIR spectrometry of evolved CO2," Materials Science and Technology, vol. 22, no. 8, pp. 908-914, 2006.

[46] C. Jin, P. A. Christensen, T. A. Egerton, E. J. Lawson, and J. R. White, "Rapid measurement of polymer photo-degradation by FTIR spectrometry of evolved carbon dioxide," Polymer Degradation and Stability, vol. 91, no. 5, pp. 1086-1096, 2006. 

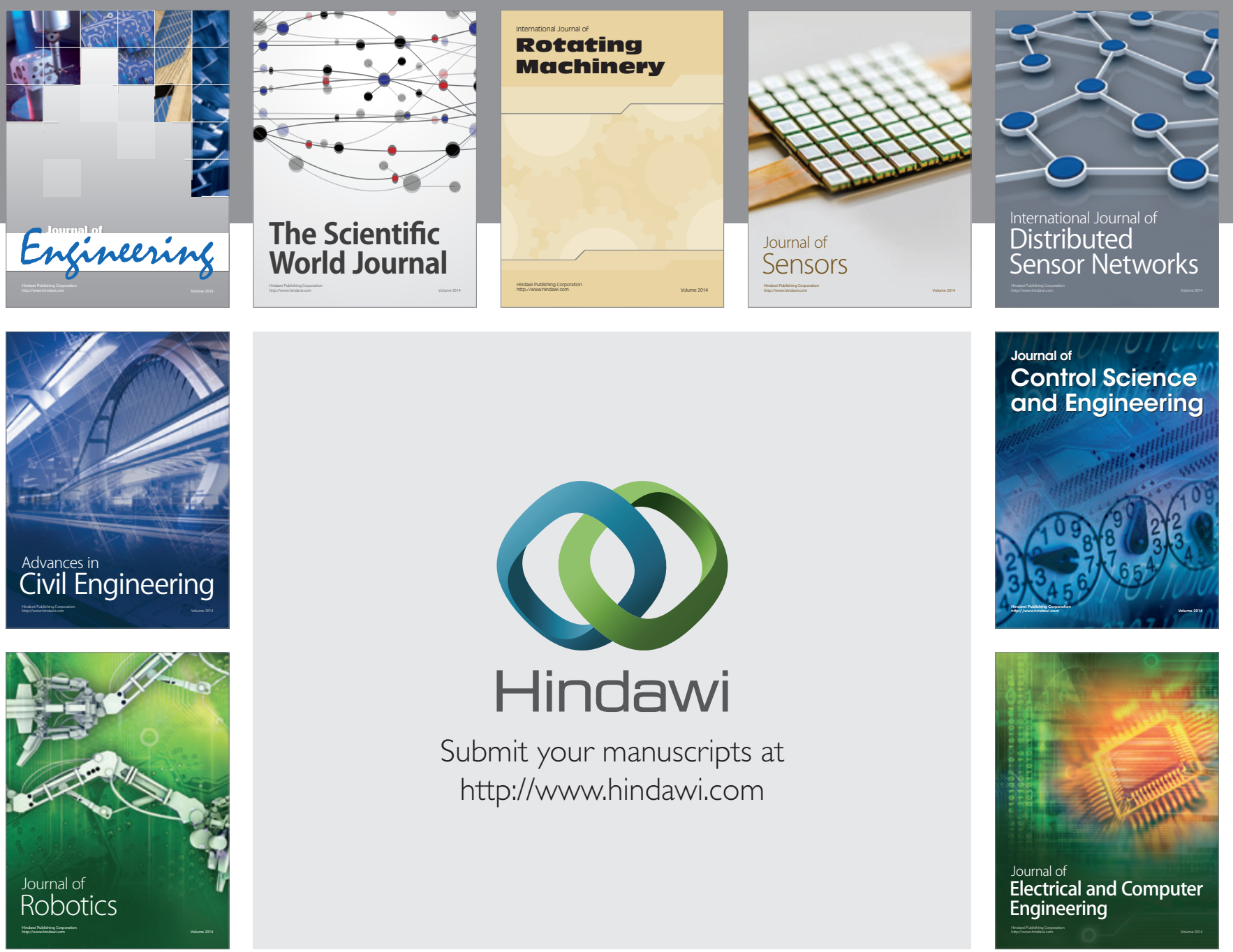

Submit your manuscripts at

http://www.hindawi.com
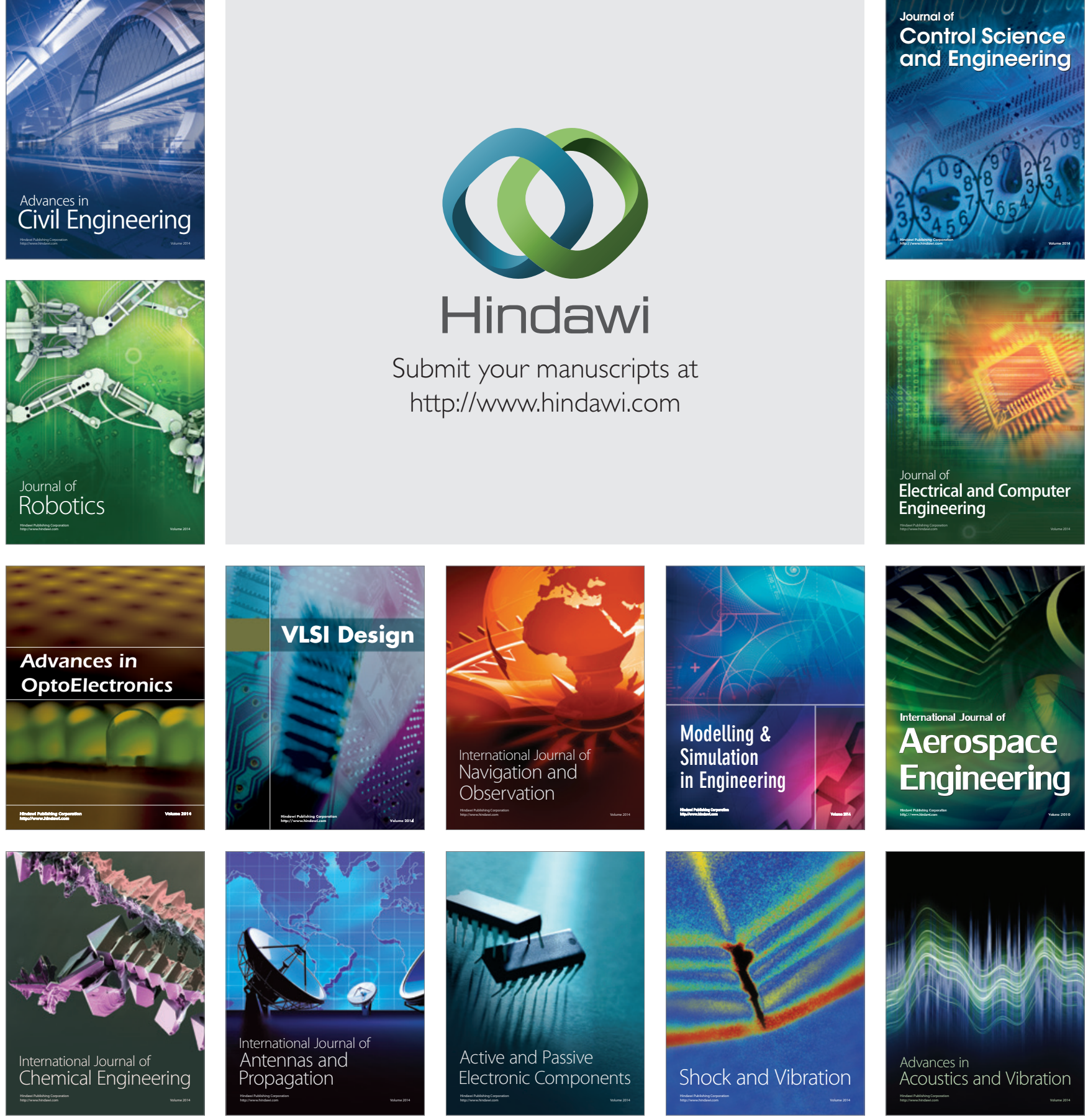